\title{
Tracing an Ancestral Mutation: Genealogical and Haplotype Analysis of the Infantile Onset Spinocerebellar Ataxia Locus
}

\author{
Teppo Varilo, ${ }^{1}$ Kaisu Nikali, ${ }^{1}$ Anu Suomalainen, ${ }^{1}$ Tuula Lönnqvist, ${ }^{2}$ and \\ Leena Peltonen ${ }^{1,3}$
}

\author{
${ }^{1}$ Department of Human Molecular Genetics, National Public Health Institute, 00300 Helsinki, Finland, \\ and ${ }^{2}$ Children's Hospital, Helsinki University Central Hospital, Helsinki, Finland
}

Infantile onset spinocerebellar ataxia (IOSCA) is a progressive neurological syndrome exhibiting an autosomal recessive pattern of inheritance. The characteristic features were described in Finland in the beginning of 1990s. Having shown that IOSCA does not segregate with any of the markers linked to other hereditary ataxias and thus represents a genetically distinct disease, we assigned the locus of this new hereditary ataxia to 10q23.3-q24.1. To approximate the age of the Finnish IOSCA mutation and to investigate the possible existence of more than one mutation underlying the disease, the ancestors of 13 IOSCA families were identified by use of church records dating back to the 1500s. The IOSCA pedigrees were frequently merged, providing support for these having one common ancestor. Analysis of the extended IOSCA haplotypes exposed ancient recombination events and revealed one core haplotype of four markers on a region of $\sim 2$ $\mathrm{cM}$, which was unequivocally present in $\mathbf{9 2 \%}$ of disease chromosomes. Both genealogical and haplotype data thus suggest that a single IOSCA ancestral mutation was introduced into the Finnish population most probably $\sim 30-40$ generations ago before the time when the general east-west migration took place within Finland.

In recent years, the search for disease genes in the Finnish population has been assisted greatly by an exceptional population history characterized by the founder effect and the isolation of the population with the resulting enrichment of some disease mutations. Accurate church records going back as far as the 16th century have provided an additional advantage. The Finnish disease heritage is a term referring to the rare disorders over-represented in the Finnish population (Norio et al. 1973). Molecular dissection of these diseases has shown that they are typically caused by one major mutation. More than 30 mostly autosomal recessive diseases belong to date to the Finnish disease heritage, and so far the disease mutation has been identified in eight of these and the chromosomal assignment in 16 (Peltonen et al. 1995).

Progress in the genetic characterization of a disease from the initial linkage to the final identification of the disease gene is still slow and

${ }^{3}$ Corresponding author.

E-MAIL leena.peltonen@ktI.fi; FAX 358-0-4744480. technically demanding. Observed recombinations and the nonrandom association of alleles at closely linked loci (linkage disequilibrium) restrict the chromosomal region under examination and greatly facilitate molecular cloning. The linkage disequilibrium analysis can be at best applied to certain types of populations: The number of original settlers must be small, and the population must have expanded without significant immigration up to present day, but must also be large enough to offer a sufficient number of patients. In the case of rare disorders, the number of patients may be so limited that an estimation of mutational age by genealogical study is a valuable tool for restricting more precisely the critical chromosomal region (Hästbacka et al. 1992; Varilo et al. 1996).

Utilizing the unique features of the Finnish population, we have performed here both a genealogical search and haplotype analyses to estimate the age of the ancestral mutation in infantile onset spinocerebellar ataxia (IOSCA), a disorder so far reported only in Finland (Koskinen et al. 1994a,b). IOSCA is a recessively inherited se- 
TRACING IHE ANCESTRAL IOSCA MUTATION

vere and progressive neurological disorder of childhood onset, characterized by cerebellar ataxia, peripheral sensory neuropathy, athetosis, hearing loss, optic atrophy, and ophthalmoplegia. A study of the birthplaces of the patients' grandparents suggested that the IOSCA chromosomes mainly originate from North Carelia, a county in eastern Finland (Koskinen et al. 1994b; Nikali et al. 1994). Linkage analysis provided evidence for the IOSCA locus assignment on chromosome 10q23.3-24.1 on a 4-cM region (Nikali et al. 1995).

Using church records, we conducted a search for the common ancestors of the IOSCA families. Extended haplotypes over the IOSCA region were constructed by analyzing eight highly polymorphic microsatellite markers on chromosome 10q23.3-q24.1. One common ancestral disease haplotype of four markers was identified on a 2-cM region, and the critical DNA region containing the IOSCA gene thus could be further defined.

\section{RESULTS}

\section{Genealogical Data}

On average, the earliest branches of the 13 IOSCA pedigrees could be traced back to the 8.8 generation. In the case of three branches of the pedigrees, the number of traceable generations was only two or three because of illegitimacy. Out of the total of 26 parents of the IOSCA patients, 10 (38\%) were found to be related with 1-3 other parents. The earliest traced common ancestors of four parents originate from the 16th century, i.e., 14 generations ago (Fig. 1), from the village of Yliveteli on the western coast of Finland. Other common ancestors, those of two parents, were found on three occasions near the eastern border in the third, seventh, and eighth generations. The birthplaces of the grandparents of the IOSCA patients were spread over a relatively wide geographical area (Fig. 2A). When the migration of the IOSCA ancestors within Finland was studied, a gradual movement from east to west was observed in addition to the typical stability of Finnish subpopulations (Fig. 2B).

\section{Haplotype Analysis}

Extended IOSCA haplotypes, constructed by analyzing eight polymorphic markers on a region of $\sim 4 \mathrm{cM}$ on 10q23.3-q24.1, revealed nine different

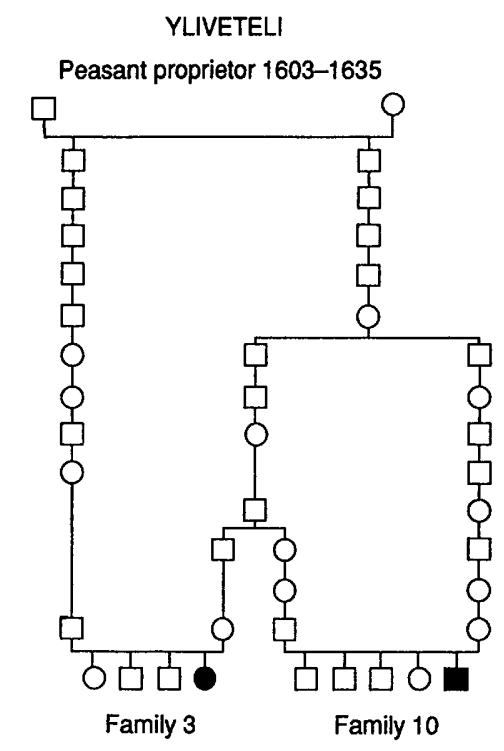

Figure 1 Pedigree of the oldest traced common ancestors of the Finnish IOSCA families originating from the parish of Yliveteli in western Finland at the end of the 1500 's.

variants. Most disease haplotypes differed from one putative founder haplotype by just a single recombination event. The suggestive founder haplotype 5-4-8-5-7-4-3-2 was present in 14 of 26 IOSCA chromosomes, and the same core haplotype 5-7-4-3 (or a slight variation of it) was found in 24 of 26 IOSCA chromosomes. Two IOSCA chromosomes carried haplotype 5-4-7-57-4-3-2, and haplotype 5-4-8-5-7-4-3-1 was similarly found in two disease chromosomes. The father of family 9 carried the disease haplotype 5-4-8-5-7-8-8-2 (Fig. 3), revealing an ancient recombination event and thus defining the telomeric end of the IOSCA locus. The centromeric boundary of the disease locus was defined by haplotype 3-4-4-5-7-4-3-3, carried by the father of family 12 , and the haplotype 5-3-2-5-74-3-2 that was detected in three disease chromosomes. A variant form of the latter, haplotype 5-3-2-5-7-3-3-5, was present in one disease chromosome. The mother of family 9 carried an additional variant disease haplotype, 5-4-8-7-12-2-2. The parental non-IOSCA chromosomes were considered to represent most relevant control chromosomes $(n=26)$. The core IOSCA haplotype was not observed in any of them.

\section{DISCUSSION}

We report here the genealogical study of 13 
VARILO ET AL.

A

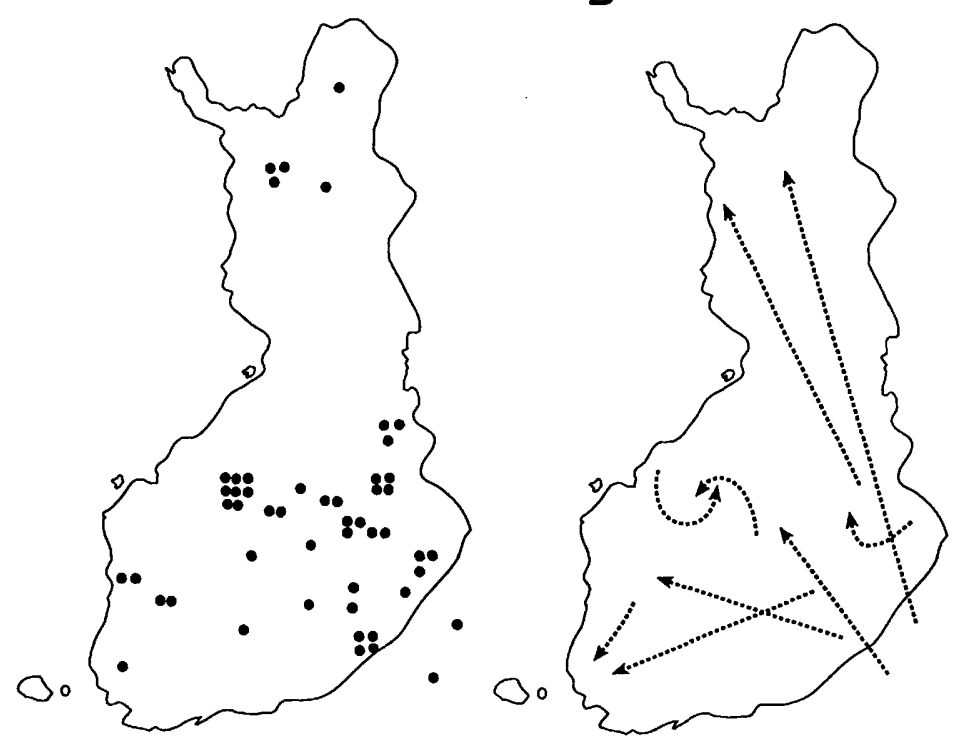

Figure $2(A)$ The birthplaces of the grandparents of the Finnish IOSCA patients on the map of Finland. $(B)$ The main migration movements of the Finnish IOSCA families' ancestors from eastern to western Finland. This resembles the great population movement of the 16th century within Finland (Norio 1973; Solantie 1988).

IOSCA families traced back to the 1500s and haplotype analysis suggesting introduction of a single ancestral mutation into the Finnish population some 750-1000 years ago. In prehistoric times, only a very small number of natives lived in Finland. Archeologic and linguistic studies have concluded that Finland was mainly populated in the beginning of the first millennium A.D. from the south over the Gulf of Finland (Norio et al. 1973; Solantie 1988; de la Chapelle 1993). For centuries, only a narrow strip of land in the coastal areas of the south and southwest was populated, and the original number of settlers must have been small. The size of the founder population was $\sim 1000$ inividuals. Even as late as the 12 th century the population is estimated to have been $\leqslant 50,000$ and since then has grown to its present $5,000,000$.

The reasons for the isolation of Finland are mostly geographical but also linguistic. The country is surrounded by the Baltic Sea to the south and west and the Arctic Ocean in the north. Dense forests, a landscape interspersed by thousands of lakes, and an arctic climate made traveling hard, and the country became sparsely populated by small subpopulations. The great east-west migration, especially from the eastern county of Savo to the western part of the country, started in the 1500 s and spread rare genes to these rural subpopulations, which remained surprisingly stable until present-day industrialization (Norio 1973; Solantie 1988). Thus within a century the inhabited land area of Finland doubled. As the settlers continued to the north, the native minority of Lapps moved away, toward the Arctic Ocean. At the end of the 1600 s almost the whole of Finland was sparsely, but permanently, populated. The routes of this east-west migration can be seen in the geographical distribution of older mutations of the Finnish disease heritage (Norio 1981).

The founder effect and genetic drift enriched some disease genes in Finland while some others, like that of phenylketonuria, relatively common elsewhere, were lost (Norio et al. 1973; Norio 1981). At the molecular level one major mutation has been shown to be responsible for the majority of disease cases, and linkage disequilibrium can be observed at significant distances in today's disease alleles. The age of some ancestral mutations of the Finnish disease heritage, such as that of aspartylglucosaminuria (AGU) (Ikonen et al. 1991; Isoniemi et al. 1995), seems to stretch back to the main colonization of the country some 2000-2500 years ago (75-100 generations) and their population distribution closely resembles the presentday population distribution of Finland. Even in relatively widespread mutations, significant linkage disequilibrium exists over an interval of 2-3 cM in Finnish disease chromosomes (Peltonen et al. 1995). However, some disease mutations, such as the variant form of late infantile neuronal ceroid lipofuscinosis (vLINCL), were introduced into the population significantly later and the birthplaces of today's patients still show regional clustering (Varilo et al. 1996). Previously, we have performed an extensive genealogical search in vLINCL, assigned to 13q (Savukoski et al. 1994). We were able to trace back all the ancestors to a cluster of five neighboring parishes and observed numerous consanguinities. Linkage disequilibrium was detected over a 11-cM interval, also supporting the concept of a relatively young mutation, which was introduced into the population only some 20-30 generations ago (Varilo et al. 1996).

The genealogy of IOSCA seems to differ from 
TRACING IHE ANCESTRAL IOSCA MUTATION

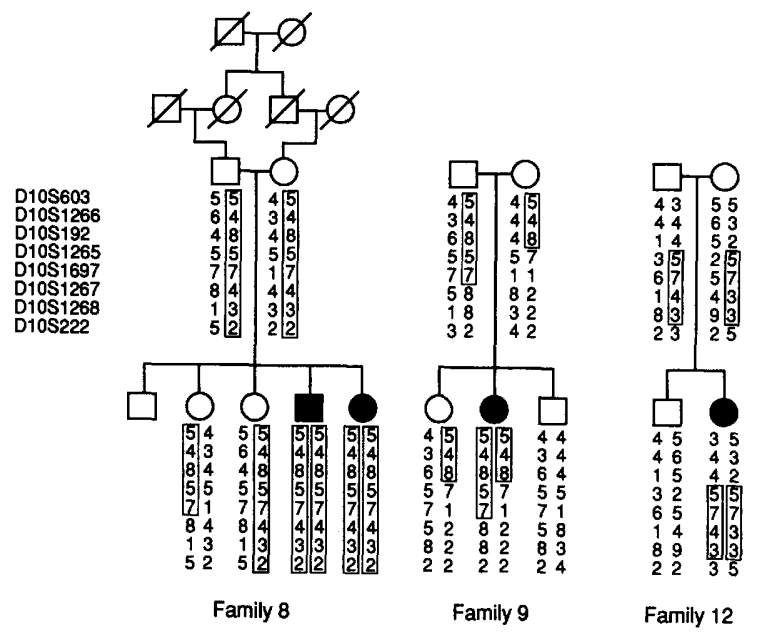

Four additional IOSCA haplotypes observed

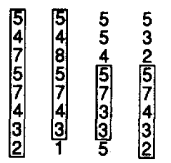

Figure 3 The extended haplotypes of eight microsatellite markers flanking the IOSCA locus. The hypothetical founder disease haplotype and traces of it are shown in boxes. In family 8 , the entire founder haplotype has remained conserved. The disease chromosomes carried by the mother of family 9 and the parents of family 12 expose ancient recombinations which suggest the disease locus to be located between the microsatellites D10S192 and D10S1265. In the case of the mother of family 12, the allele 3 (instead of 4) of the marker D10S1267 in the core haplotype was considered to be a novel mutation of one $A C$ in length, an assumption supported by the surrounding haplotype.

that of vLINCL. No obvious clustering of ancestors was observed in the search, which, like that of vLINCL, spanned 14 generations. However, the distribution of the ancestors' birthplaces does not reflect the distribution of the current Finnish population, either. The ancestors originated from a relatively wide geographical area across southern and central Finland, the distribution closely resembling the late settlement movement of the 1500 s and supporting the hypothesis that the disease alleles were introduced into subpopulations during this migration wave to the inland. The observed consanguinity was typically between the mother and father of the same family, whereas individual IOSCA families did not merge until as early as the 1500s. Furthermore, the chromosomal region revealing significant linkage dis- equilibrium was found to be only $4 \mathrm{cM}$ (Nikali et al. 1995), a relatively short interval when compared with $11 \mathrm{cM}$ in the vLINCL chromosomes. It seems reasonable to conclude that the majority of Finnish IOSCA patients originate from one ancestor mutation, which was introduced into the population earlier than vLINCL but later than AGU, perhaps some 30-40 generations, or 7501000 years, ago. We cannot be entirely sure whether our pedigrees depict the true inheritance routes of the IOSCA gene via common ancestors to the parents. Illegitimacy, missing church archives, the unreliability of taxation registers, and even misinterpretations of ancient handwriting may introduce errors in the pedigrees and in interpretation of the true routes of the disease gene. However, genealogical and haplotype analyses resulted in a similar approximation of the age range of this disease mutation.

Multiplicity of the subpopulations revealing IOSCA ancestors and the regional distribution of these subpopulations resemble closely the situation in some other disorders of the Finnish disease heritage. These include autoimmune polyendocrinopathy-candidosis-ectodermal dystrophy (APECED) and progressive myoclonus epilepsy (PME). It could be argued that these mutations were introduced into the population within a relatively short time of each other. Also, the intervals demonstrating linkage disequilibrium in these diseases-3 cM in APECED (Aaltonen et al. 1994) and $5 \mathrm{cM}$ in PME (Lehesjoki et al. 1993)-are of the same range, especially when considering the different density and coverage of the polymorphic markers analyzed in the disease chromosomes. This would further support the idea that these various disease mutations have had an equal length of time to spread over the relatively large country and that the diffusion followed similar routes, reflecting the major movements of the relatively small population.

In an isolated population, the identification of disease-associated haplotypes provides an efficient tool for further restriction of the critical chromosomal region in respect to nearby marker loci. Following the introduction of a disease chromosome into an isolate, a limited number of recombinations occur, leaving the ancestral haplotype well conserved and easily detectable at significant intervals on DNA strands. Extended IOSCA haplotypes with eight microsatellites revealed one ancient founder haplotype, 5-4-8-57-4-3-2, which had remained conserved in the majority (54\%) of today's disease chromosomes. 


\section{VARILO ET AL.}

Two haplotypes, 5-4-7-5-7-4-3-2 and 5-4-8-57-4-3-1, most probably originate from the same ancestral haplotype: the former through a new mutation changing allele 8 to 7 , and the latter through a single recombination event. Three individuals carrying the haplotype 5-3-2-5-7-43-2 and one with its variant form 5-3-2-5-7-33-5 originated from two neighboring parishes in eastern Finland, and were found to be related. These two haplotypes most likely descend from one and the same ancestral chromosome revealing an ancient recombination event when compared to the founder haplotype. The variant form 5-7-3-3 of the core haplotype 5-7-4-3 present in two disease chromosomes most probably diverged from the main core haplotype by a insertion of one $\mathrm{AC}$ repeat allele 4 to generate the next larger allele 3 . In the case of APECED, the major core haplotype of $-0.3 \mathrm{cM}$ is found in $75 \%$ of today's disease chromosomes, in contrast to $6 \%$ in control chromosomes. With one marker, $94 \%$ of the present APECED chromosomes have been found to carry the same allele found at a frequency of $60 \%$ in control chromosomes, suggesting that at least $85-90 \%$ of Finnish APECED cases are caused by this major mutation (Björses et al., 1996). In the case of PME, $64 \%$ of the present disease haplotypes share the alleles at four marker loci, while this putative founder haplotype has been observed in only $1 \%$ of control chromosomes (Lehesjoki et al. 1993).

An interesting exception to the majority of today's IOSCA chromosomes, which exhibit at least part of the ancestral founder chromosome, is a disease haplotype variant form, 5-4-8-7-1$2-2-2$, carried by the mother of family 9 . This haplotype can be explained by a single recombination event altering the telomeric part of the disease haplotype, which would restrict the critical chromosomal region centromerically between the markers D10S1265 and D10S192. However, an independent IOSCA mutation cannot be fully excluded because the ancestors of the parent carrying this disease haplotype were not found to be related to any of the others, and four generations ago one of her ancestors moved from Novgorod, Russia, leaving a small possibility of an other mutation of eastern origin.

Because of the population history of Finland, one major mutation is characteristically found to be responsible for diseases belonging to the Finnish disease heritage. At the molecular level this has so far been proven for six diseases, all revealing one major mutation responsible for the ma- jority of cases (Peltonen et al. 1995). Even in AGU, which is one of the oldest of the Finnish diseases, $98 \%$ of the disease alleles carry the same disease mutation (Ikonen et al. 1991). In conclusion, in Finland and similarly in other genetic isolates, detailed analysis of linkage disequilibrium intervals in inherited diseases with a defined marker map density offers a highly reliable tool for determination of the history of the mutation.

\section{METHODS}

\section{Families}

A total of 19 IOSCA patients in all the so far diagnosed 13 families were identified by one clinician in accordance with published criteria (Koskinen et al. 1994, Nikali et al. 1994). All the families were included in both the genealogical study and haplotype analysis.

\section{Genealogical Studies}

The genealogical study was performed in accordance with published criteria (Varilo et al. 1996). The names, dates, and places of birth of the patients parents were utilized to trace ancestors up to 1850 from local church registries. Microfilm copies in the Finnish National Archives were used for all later periods. The parish history of Kokkola, based on less reliable land and taxation registers, offered additional data from the 16th and 17 th centuries (see appendix in work of Virrankoski 1961, pp. 693-702).

\section{DNA Samples and Microsatellite Markers}

Total DNA was extracted from leukocytes of frozen peripheral venous blood, or in the case of a deceased patient, from paraffin-embedded autopsy samples in accordance with standard procedures (Vandenplas et al. 1984; Shibata et al. 1988). Eight polymorphic microsatellite markers on $10 \mathrm{q}$, with sequences obtained from the Genethon Resource Center (Gyapay et al. 1994) were analyzed as described before (Nikali et al. 1995). Haplotypes were constructed manually, assuming the minimum number of recombinations in each family. The putative IOSCA founder haplotype was reconstructed by assuming the minimum number of historical recombinations. The order of the markers was basically the same as in the Genethon microsatellite map (Gyapay et al. 1994), however, and modified only by the obligatory recombination events observed in the IOSCA families.

\section{ACKNOWLEDGMENTS}

We are grateful to the Finnish IOSCA families for providing data for this study. The financial support of the Academy of Finland, the Foundation for Pediatric Research (Ulla Hjelt Fund), and the Rinnekoti Research Foundation are acknowledged. 


\section{IRACING IHE ANCESIRAL IOSCA MUTATION}

The publication costs of this article were defrayed in part by payment of page charges. This article must therefore be hereby marked "advertisement" in accordance with 18 USC section 1734 solely to indicate this fact.

\section{REFERENCES}

Aaltonen, J., P. Björses, L. Sandkuijl, J. Perheentupa, L. Peltonen. 1994. An autosomal locus causing autoimmune disease: Autoimmune polyglandular disease type I assigned to chromosome 21. Nature Genet. 8: $83-87$.

Björses, P., J. Aaltonen, A. Vikman, J. Perheentupa, G. Chiumello, N. Dahl, P. Heideman, J.J.G. HoornegNijman, L. Mathivon, P.E. Mullis, M. Pohl, M. Zitzen, G. Romeo, C.S. Smith, J. Solyom, J. Zlotogora, and L. Peltonen. 1996. Genetic homogeneity of autoimmune polyglandular disease type I. Am. J. Hum. Genet. (in press).

de la Chapelle, A. Disease gene mapping in isolated human populations: The example of Finland. 1993. I. Med. Genet. 30: 857-865.

Gyapay, G., J. Morrisette, A. Vignal, C. Dib, C. Fizames, P. Millasseau, S. Marc, G. Bernardi, M. Lathrop, and J. Weissenbach. 1994. The 1993-94 Gènèthon human genetic linkage map. Nature Genet. 7: 246-339.

Hästbacka J., A. de la Chapelle, I. Kaitila, P. Sistonen, A. Weaver, and E. Lander. 1992. Linkage disequilibrium mapping in isolated founder populations: diastrophic dysplasia in Finland. Nature Genetics 2: 204-211.

Ikonen, E., M. Baumann, K. Grön, A.C. Syvänen, N. Enomaa, R. Halila, P. Aula, and L. Peltonen. 1991. Aspartylglucosaminuria: cDNA encoding human aspartylglucosaminidase and the missense mutation causing the disease. EMBO J. 10: 51-58.

Isoniemi, A., M. Hietala, P. Aula, A. Jalanko, and L. Peltonen. 1995. Identification of a novel mutation causing aspartylglucosaminuria reveals a mutation hotspot region in the aspartylglucosaminidase gene. Hum. Mutat. 5: 318-326.

Koskinen, T., K. Sainio, J. Rapola, H. Pihko, and A. Paetau. 1994a. Sensory neuropathy in infantile onset spinocerebellar ataxia (IOSCA). Muscle Nerve 17: 509-515.

Koskinen, T., P. Santavuori, K. Sainio, A-K. Kallio, and H. Pihko. 1994b. Infantile onset spinocerebellar ataxia with sensory neuropathy: a new inherited disease. J. Neurol. Sci. 121: $50-56$.

Lehesjoki, A.E., M. Koskiniemi, R. Norio, S. Tirrito, P. Sistonen, E. Lander, and A. de la Chapelle. 1993. Localization of the EPMI gene for progressive myoclonus epilepsy on chromosome 21: Linkage disequilibrium allows high resolution mapping. Hum. Mol. Genet. 2: $1229-1234$.
Nikali, K., T. Koskinen, A. Suomalainen, H. Pihko, and L. Peltonen. 1994. Infantile onset spinocerebellar ataxia represents an allelic disease distinct from other hereditary ataxias. Pediatr. Res. 36: 607-612.

Nikali, K., A. Suomalainen, J. Terwilliger, T. Koskinen, J. Weissenbach, and L. Peltonen. 1995. Random search for shared chromosomal regions in four affected individuals: The assignment of a new hereditary ataxia locus. Am.J. Hum. Genet. 56: 1088-1095.

Norio, R. 1981. Diseases of Finland and Scandinavia. In Biocultural aspects of disease (ed. H.R. Rothschild), pp. 359-414. Academic Press, New York, NY.

Norio, R., H.R. Nevanlinna, and J. Perheentupa. 1973. Hereditary diseases in Finland. Annals Clin. Res. 5: 109-141.

Peltonen, L., P. Pekkarinen, and J. Aaltonen. 1995. Messages from an isolate: Lessons from the Finnish gene pool. Biol. Chem. 376: 697-704.

Savukoski, M., M. Kestilä, R. Williams, I. Järvelä, J. Sharp, J. Harris, P. Santavuori, M. Gardiner, and L. Peltonen. 1994. Defined chromosomal assignment of CLN5 demonstrates that at least four genetic loci are involved in the pathogenesis of human ceroid lipofuscinoses. Am. J. Hum. Genet. 55: 695-701.

Shibata, D.K., N. Arnheim, and W.J. Martin. 1988. Detection of human papilloma virus in paraffin-embedded tissue using the polymerase chain reaction. J. Exp. Med. 167: 225-230.

Solantie, R. 1988. Climatic conditions for the cultivation of rye with reference to the history of settlement in Finland. Fennoscandia archaeologica $\mathbf{V}: 3-20$.

Vandenplas, S., I. Wiid, A. Grobler-Rabie, K. Brebner, M. Ricketts, G. Wallis, A. Bester, C. Boyd, and C. Mathew. 1984. Blot hybridization analysis of genomic DNA. J. Med. Genet. 21: 164-172.

Varilo, T., M. Savukoski, R. Norio, P. Santavuori, L. Peltonen, and I. Järvelä. 1996. Tracing ancestors for CLN5 mutation: Genealogical and linkage disequilibrium analysis in the Finnish population. Am. J. Hum. Genet. 58: $506-512$.

Virrankoski P. 1961. Kokkolan pitäjä yläosan historia. Keski-Pohjanmaan kirjapaino oy, Kokkola.

Received June 17, 1996; accepted in revised form July 23, 1996. 


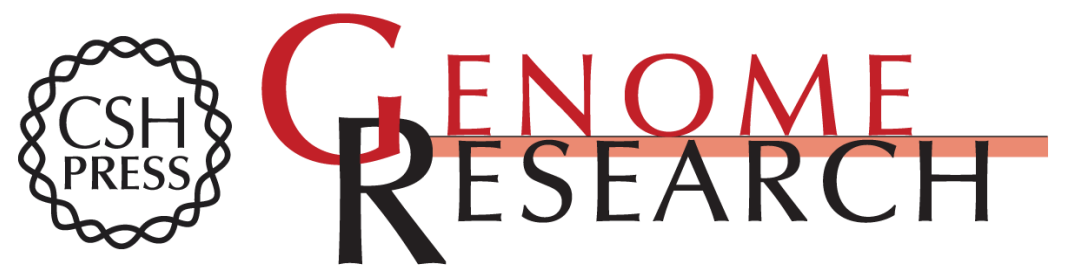

\section{Tracing an ancestral mutation: genealogical and haplotype analysis of the infantile onset spinocerebellar ataxia locus.}

T Varilo, K Nikali, A Suomalainen, et al.

Genome Res. 1996 6: 870-875

Access the most recent version at doi:10.1101/gr.6.9.870

References This article cites 17 articles, 3 of which can be accessed free at:

http://genome.cshlp.org/content/6/9/870.full.html\#ref-list-1

\section{License}

Email Alerting Receive free email alerts when new articles cite this article - sign up in the box at the Service top right corner of the article or click here.

\section{Affordable, Accurate Sequencing.}

To subscribe to Genome Research go to:

https://genome.cshlp.org/subscriptions 